between SUVmax in thoracic and abdominal aorta on PET/CT and ESR at diagnosis ( $r=0.63 p=0.002$ and $r=0.77 p<0.001$, respectively) and SUVmax in thoracic aorta and CRP $(r=0.50 \mathrm{p}=0.026)$. PET/CT $(-)$ patients had more frequent disease flares during the follow-up (4/6 vs. $5 / 23 p=0.035$ OR $=7.2$ (1.01- 51)). Three distinct subgroups were defined by implementing both ACR criteria and PET/CT positivity. Among ACR (+) patients $(n=20)$; comparison of PET/CT $(+)$ $(n=14)$ and PET/CT $(-)(n=6)$ patients did not show any difference in age of diagnosis, presence of polymyalgia rheumatica (PMR), flare rate and damage scores. Among PET/CT $(+)$ patients $(n=23)$, the mean age at diagnosis was higher, PMR and bilateral axillary artery involvement was more frequent in ACR (+) group $(n=14)$ (Table 1).

Conclusion: PET/CT is increasingly used in the diagnosis and assessment of GCA in our center. The level of FDG uptake of the vessel wall in PET/CT correlates with the acute phase response. Flare was rarely observed in PET/CT $(+)$ patients at diagnosis. Axillary artery involvement detected on PET/CT may be associated with the classical GCA clinic in ACR(+) patients (1). PET/CT (+) patients who does not met ACR criteria seems to have a diverse clinic features like young age and rare presence of PMR. PET/CT findings may be helpful in recognizing subgroups and predicting prognosis of GCA although prospective studies with follow-up scans are warranted.

REFERENCES:

[1] Grayson PC, Maksimowicz-McKinnon K, Clark TM, Tomasson G, Cuthbertson D, Carette S, et al. Distribution of arterial lesions in Takayasu's arteritis and giant cell arteritis. Annals of the rheumatic diseases. 2012;71(8):1329-34.

Table 1. Comparison of patients who fulfilled and not fulfilled ACR 1990 classification criteria among PET/CT (+) patients.

\begin{tabular}{|c|c|c|c|c|}
\hline & $\begin{array}{c}\text { ACR (+) PET/ } \\
\text { CT (+) } \\
(n=14)\end{array}$ & $\begin{array}{c}\text { ACR (-) PET/ } \\
\text { CT (+) } \\
(n=9)\end{array}$ & $\mathrm{p}$ & $\begin{array}{c}\text { OR } \\
(\% 95 \mathrm{Cl})\end{array}$ \\
\hline Age at diagnosis & $68,8 \pm 4,5$ & $63.3 \pm 9,2$ & 0.004 & \\
\hline PMR & 10 & 2 & 0.021 & $2.5(1-6.1)$ \\
\hline History of flare & 4 & 1 & NS & \\
\hline CRP at diagnosis & $75,1 \pm 30,6$ & $130,8 \pm 93,4$ & 0.024 & \\
\hline ESR at diagnosis & $93,9 \pm 28,1$ & $112,5 \pm 21,2$ & NS & \\
\hline Brachiocephalic artery & 9 & 6 & NS & \\
\hline Right subclavian & 8 & 5 & NS & \\
\hline Lef subclavian & 9 & 5 & NS & \\
\hline Right carotid & 8 & 5 & NS & \\
\hline Left carotid & 9 & 6 & NS & \\
\hline Right axillary & 7 & 0 & 0.011 & $2(1.18-3.3)$ \\
\hline Bilateral axillary & 6 & 0 & 0.022 & $1.75(1.1-2.7)$ \\
\hline Thoracic aorta SUVmax (mean) & $3,9 \pm 1,1$ & $4,6 \pm 1,3$ & NS & \\
\hline Abdominal aorta SUVmax (mean) & $4,5 \pm 1,2$ & $5,3 \pm 1,8$ & NS & \\
\hline
\end{tabular}

Disclosure of Interests: None declared

DOI: 10.1136/annrheumdis-2021-eular.2036

\section{AB0370 UTILITY OF CRP AND ESR IN THE DIAGNOSIS OF GIANT CELL ARTERITIS RELAPSE IN A PHASE 2 TRIAL OF MAVRILIMUMAB}

S. Unizony ${ }^{1}$, M. C. Cid $^{2}$, E. Brouwer ${ }^{3}$, L. Dagna ${ }^{4,5}$, B. Dasgupta ${ }^{6}$, B. Hellmich ${ }^{7}$ E. Molloy ${ }^{8}$, C. Salvarani ${ }^{9}$, B. C. Trapnell ${ }^{10}$, K. J. Warrington ${ }^{11}$, I. Wicks ${ }^{12}$, M. Samant ${ }^{13}$, T. Zhou ${ }^{13}$, L. Pupim ${ }^{13}$, J. F. Paolini ${ }^{13} .{ }^{1}$ Massachusetts General Hospital, Vasculitis and Glomerulonephritis Center, Department of Rheumatology, Allergy and Immunology, Boston, United States of America; ${ }^{2}$ Hospital Clínic, University of Barcelona, Institut d'Investigacions Biomèdiques August Pi i Sunyer (IDIBAPS), Vasculitis Research Unit, Department of Autoimmune Diseases, Barcelona, Spain; ${ }^{3}$ University of Groningen, University Medical Center, University of Groningen, University Medical Center, Groningen, Netherlands; ${ }^{4}$ IRCCS San Raffaele Scientific Institute, Unit of Immunology, Rheumatology, Allergy and Rare Diseases (UnIRAR), Milan, Italy; ${ }^{5}$ Vita-Salute San Raffaele University, Vita-Salute San Raffaele University, Milan, Italy; ${ }^{6}$ Southend University Hospital NHS Foundation Trust, Southend University Hospital NHS Foundation Trust, Westcliff-on-sea, United Kingdom; ${ }^{7}$ Medius Kliniken, Department of Internal Medicine, Rheumatology, and Immunology, Kirchhelm unter Teck, Germany; ${ }^{8}$ St Vincent's University Hospital, St Vincent's University Hospital, Dublin, Ireland; ${ }^{9}$ Arcispedale Santa Maria Nuova, Arcispedale Santa Maria Nuova, Reggio Emilia, Italy; ${ }^{10}$ Cincinnati Children's Hospital, Translational Pulmonary Science Center, Cincinnati, United States of America; ${ }^{11}$ Mayo Clinic, Mayo Clinic, Rochester, United States of America; ${ }^{12}$ Walter \& Eliza Hall Institute \& Melbourne Health, Walter \& Eliza Hall Institute \& Melbourne Health, Melbourne, Australia; ${ }^{13}$ Kiniksa Pharmaceuticals Corp., Clinical Development, Lexington, United States of America
Background: No universally accepted definition of flare currently exists in giant cell arteritis (GCA). Although relapses are defined mostly on clinical grounds (recurrence of GCA-related signs/symptoms), C-reactive protein (CRP) and erythrocyte sedimentation rate (ESR) help clinicians assess disease activity. In fact, $>70 \%$ of patients on glucocorticoids (GCs) alone have increased CRP or ESR when the disease is active. In contrast, tocilizumab, given its IL-6-blockade effect in the liver, rapidly reduces CRP and ESR levels, rendering them unreliable for disease activity monitoring. Mavrilimumab - a GM-CSF receptor $\alpha$ inhibitor with demonstrated efficacy in a Phase 2 GCA trial ${ }^{1}$ - downregulates inflammation upstream of IL-6. We hypothesized that mavrilimumab would not interfere with the utility of CRP and ESR in monitoring disease activity and in identifying GCA relapse.

Objectives: To analyze the relationship between CRP/ESR and clinical disease activity in GCA patients treated with mavrilimumab.

Methods: New-onset and relapsing GCA patients with active disease were recruited. GC-induced remission (no GCA symptoms and CRP $<1 \mathrm{mg} / \mathrm{dL}$ or ESR $<20 \mathrm{~mm} / \mathrm{hr}$ ) was required by baseline. Patients were randomized 3:2 to mavrilimumab $150 \mathrm{mg}$ or placebo subcutaneously every 2 weeks plus a protocol-defined 26-week prednisone taper. The primary efficacy endpoint was time to relapse by Week 26. Relapse (adjudicated) was defined as recurrent GCA-related signs/ symptoms, including new/worsening vasculitis on imaging, concurrent with CRP $\geq 1 \mathrm{mg} / \mathrm{dL}$ and/or ESR $\geq 30 \mathrm{~mm} / \mathrm{hr}$. CRP and ESR were also measured periodically during the trial.

This post hoc analysis assessed the association of recurrent GCA-related signs/ symptoms with concurrent CRP or ESR elevation post-randomization by treatment arm. We also assessed the proportion of patients with CRP or ESR elevation without GCA-related signs/symptoms up to Week 26.

Results: Seventy patients were enrolled (mavrilimumab, $\mathrm{N}=42$; placebo, $\mathrm{N}=28$ ). The association of CRP or ESR elevation with unequivocal GCA-related signs/ symptoms post-randomization was consistent regardless of treatment arm: 8/8 in the mavrilimumab group and $13 / 13$ in the placebo group (Table 1). During relapse, median (range) CRP was $1.8(1.4-8.4) \mathrm{mg} / \mathrm{dL}$ (mavrilimumab group) and $1.8(1.1$ - 9.0) $\mathrm{mg} / \mathrm{dL}$ (placebo group). Corresponding ESR values were $39.5(30-102) \mathrm{mm} / \mathrm{hr}$ (mavrilimumab group) and $49(31-101) \mathrm{mm} / \mathrm{hr}$ (placebo group). Four mavrilimumab recipients had self-limited, equivocal GCA-related signs/symptoms without concurrent CRP or ESR elevation; all 4 completed the prespecified GC taper by Week 26 without need for rescue GCs, so relapse was not confirmed. At least 1 elevated CRP or ESR value in the absence of GCA-related signs/symptoms was observed in $58.8 \%$ of mavrilimumab recipients and $93.3 \%$ of placebo recipients by Week 26 .

Conclusion: The observed association of CRP or ESR elevation with GCA-related signs/symptoms is consistent with the upstream mechanism and supports the utility of the stringent protocol definition of relapse. The frequency and mag nitude of CRP and ESR elevations at relapse were similar in both treatment groups, suggesting that CRP and ESR remain useful in assessments of disease activity in mavrilimumab-treated patients. CRP and ESR elevations without GCA-related signs/symptoms occurred more often in placebo recipients. REFERENCES:

[1] Cid, Unizony et al. Arthritis Rheumatol. 2020; 72 (suppl 10)

Table 1. CRP and ESR levels in patients with or without GCA relapse

\begin{tabular}{|c|c|c|c|c|}
\hline \multirow[t]{3}{*}{ Assessment $^{\S}$} & Mavrilimumab & Placebo & Mavrilimumab & Placebo \\
\hline & $\mathrm{N}=42$ & $\mathrm{~N}=\mathbf{2 8}$ & $\mathrm{N}=42$ & $\mathrm{~N}=\mathbf{2 8}$ \\
\hline & \multicolumn{2}{|c|}{ With Relapse } & \multicolumn{2}{|c|}{ Without Relapse } \\
\hline \# of patients & $8(19.1)$ & $13(46.4)$ & $34(81.0)$ & $15(53.6)$ \\
\hline Elevated CRP* or ESR† & $8(100.0)$ & $13(100.0)$ & $20(58.8)$ & $14(93.3)$ \\
\hline Elevated CRP* & 7 (87.5) & $10(76.9)$ & $10(29.4)$ & $11(73.3)$ \\
\hline Median (range) mg/dL & $1.8(1.4-8.4)$ & $1.8(1.1-9.0)$ & $2.6(1.3-7.0)$ & $2.0(1.0-6.6)$ \\
\hline Elevated ESR $\dagger$ & $6(75.0)$ & $9(69.2)$ & $16(47.1)$ & $10(66.7)$ \\
\hline Median (range) $\mathrm{mm} / \mathrm{hr}$ & $39.5(30-102)$ & $49.0(31-101)$ & $41.5(30-110)$ & $53.5(30-82)$ \\
\hline
\end{tabular}

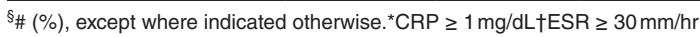

Disclosure of Interests: Sebastian Unizony Consultant of: Janssen and Kiniksa, Grant/research support from: Genentech, Maria C. Cid Speakers bureau: Roche and Kiniksa, Paid instructor for: GSK and Vifor, Consultant of: Janssen, GSK and Abbvie, Grant/research support from: Kiniksa, Elisabeth Brouwer Speakers bureau: Dr. E.Brouwer as an employee of the UMCG received speaker fees and consulting fees from Roche in 20172018 which were paid to the UMCG., Consultant of: Dr. E.Brouwer as an employee of the UMCG received speaker fees and consulting fees from Roche in 20172018 which were paid to the UMCG., Lorenzo Dagna Speakers bureau: Abbvie, Amgen, Biogen, BMS, Celltrion, Galapagos, Glaxo SmithKline, Novartis, Pfizer, Roche, Sanofi-Genzyme, 
SOBI, Consultant of: Abbvie, Amgen, Biogen, BMS, Celltrion, Galapagos, Glaxo SmithKline, Novartis, Pfizer, Roche, Sanofi-Genzyme, SOBI; clinical trial for Kiniksa, Grant/research support from: Abbvie, Amgen, BMS, Celltrion, Galapagos, Novartis, Pfizer, Roche, Sanofi-Genzyme, SOBI, Merk Sharp \&Dohme, Janssen, Kiniksa, Bhaskar Dasgupta Paid instructor for: Educational grant symposium/workshop for Roche-chugai, Sanofi, and Abbvie, Consultant of: CI UK for the Kiniksa trial, Grant/research support from: Educational grant symposium/ workshop for Roche-chugai, Sanofi, and Abbvie, Bernhard Hellmich Consultant of: Honoraria paid to the institution for participation in the clinical trial, Eamonn Molloy: None declared, Carlo Salvarani: None declared, Bruce C. Trapnell Consultant of: Consultant member of DSMB for Kiniksa., Kenneth $\mathrm{J}$ Warrington Consultant of: Clinical trial support from Eli Lilly and Kiniksa, lan Wicks: None declared, Manoj Samant Shareholder of: Kiniksa Pharmaceuticals, Employee of: Kiniksa Pharmaceuticals, Teresa Zhou Shareholder of: Kiniksa Pharmaceuticals, Employee of: Kiniksa Pharmaceuticals, Lara Pupim Shareholder of: Kiniksa Pharmaceuticals, Employee of: Kiniksa Pharmaceuticals, John F. Paolini Shareholder of: Kiniksa Pharmaceuticals, Employee of: Kiniksa Pharmaceuticals DOI: 10.1136/annrheumdis-2021-eular.2221

\section{AB0371 PATIENTS WITH PROLONGED SYMPTOMS BEFORE GCA DIAGNOSIS DO NOT INCUR HIGHER RATES OF VISUAL LOSS}

V. Yang ${ }^{1}$, C. Mcmaster ${ }^{1,2}$, C. Owen ${ }^{1,2}$, J. Leung ${ }^{1,2}$, R. Buchanan ${ }^{1,2}$, D. Liew ${ }^{1,2}$. ${ }^{1}$ Austin Health, Rheumatology, Heidelberg, Australia; ${ }^{2}$ The University of Melbourne, Medicine, Parkville, Australia

Background: Giant cell arteritis (GCA), if left untreated, confers the threat of serious cranial ischaemic complications including permanent visual loss. Although achieving a prompt and accurate diagnosis remains challenging, early diagnosis is viewed as being paramount in preventing significant morbidity. ${ }^{1}$ This raises the question of whether GCA patients are at greater risk of developing visual sequelae if there is a longer window between symptom onset and presentation.

Objectives: To compare the frequency of lasting visual loss in patients diagnosed with GCA undergoing temporal artery biopsy (TAB) within three months and after three months of symptom onset.

Methods: Patients who underwent TAB from January 2011 to November 2020 were identified from the pathology database of an Australian rheumatology referral centre. The diagnosis of GCA was established for each patient based on either positive TAB or, in the setting of negative TAB, clinical diagnosis by a rheumatologist. Baseline demographics, symptoms and major confounders including age, sex, history of polymyalgia rheumatica or inflammatory arthritis, headache, jaw pain, fatigue, temporal artery tenderness or diminished pulse, and number of 1990 American College of Rheumatology (ACR) classification criteria for $\mathrm{GCA}^{2}$ fulfilled - were manually extracted from electronic medical records, as was the duration between onset of GCA symptoms and TAB, and the presence of visual loss before and after TAB. Logistic regression log-likelihood tests were used to examine the two cohorts presenting before and after three months.

Results: There were 167 patients who underwent TAB during the study period with accessible clinical information. Of these, 31 (19\%) had a delayed presentation of greater than three months from symptom onset. There were no statistical differences in patient demographics between the two groups (Table 1). No patients with delayed presentation experienced lasting, objective visual loss. In contrast, there were three cases in the cohort of patients who presented more promptly; these included two patients who developed permanent unilateral blindness, and one who experienced unilateral vision loss with some improvement at three months of follow-up.

Table 1. Patient characteristics by time from symptom onset to TAB.

\begin{tabular}{lccc}
\hline & $\begin{array}{c}\text { Presentation }<3 \\
\text { months }\end{array}$ & $\begin{array}{c}\text { Presentation } \geq 3 \\
\text { months }\end{array}$ & p-value \\
\hline Age (years) & $73.45 \pm 10.06$ & $69.84 \pm 10.75$ & 0.080 \\
Female & $92(67.65 \%)$ & $20(64.52 \%)$ & 0.738 \\
History of polymyalgia rheumatica & $23(16.91 \%)$ & $4(12.90 \%)$ & 0.586 \\
History of inflammatory arthritis & $6(4.41 \%)$ & $2(6.45 \%)$ & 0.633 \\
Headache & $110(80.88 \%)$ & $23(74.19 \%)$ & 0.406 \\
Jaw pain & $37(27.21 \%)$ & $5(16.13 \%)$ & 0.206 \\
Fatigue & $28(20.59 \%)$ & $6(19.35 \%)$ & 0.878 \\
Temporal artery tenderness or diminished & $46(33.82 \%)$ & $11(35.48 \%)$ & 0.860 \\
$\quad$ pulse & $2.83 \pm 0.99$ & $2.58 \pm 0.89$ & 0.199 \\
ACR classification criteria & & & \\
\hline
\end{tabular}

Conclusion: GCA patients with a lengthier course of symptoms before diagnosis did not experience any enduring visual loss. This may reflect a pattern of more aggressive disease leading to earlier presentation, but further study should explore whether longer symptom duration before diagnosis necessitates a higher degree of clinical concern.

\section{REFERENCES:}

[1] Font C, Cid MC, Coll-Vinent B, López-Soto A, Grau JM. Clinical features in patients with permanent visual loss due to biopsy-proven giant cell arteritis. Br J Rheumatol. 1997 Feb;36(2):251-4. doi: 10.1093/rheumatology/36.2.251. PMID: 9133940.

[2] Hunder GG, Bloch DA, Michel BA, Stevens MB, Arend WP, Calabrese LH, Edworthy SM, Fauci AS, Leavitt RY, Lie JT, et al. The American College of Rheumatology 1990 criteria for the classification of giant cell arteritis. Arthritis Rheum. 1990 Aug;33(8):1122-8. doi: 10.1002/art.1780330810. PMID: 2202311.

Disclosure of Interests: None declared

DOI: 10.1136/annrheumdis-2021-eular.2234

\section{AB0372 TOCILIZUMAB WAS EFFECTIVE IN REFRACTORY ARTERIAL INVOLVEMENT OF BEHCET'S DISEASE: A REAL-LIFE SINGLE- CENTER EXPERIENCE IN CHINA}

H. Zhong ${ }^{1}$, T. Liu ${ }^{1}$, Y. Liu ${ }^{1}$, X. Zhang ${ }^{1}$, Y. Zhou ${ }^{1}$, Y. Su ${ }^{1} .{ }^{1}$ Peking University People's Hospital, Department of Rheumatology and Immunology, Beijing, China

Background: Behcet's disease (BD) is a chronic and relapsing vasculitis, in which major vessel involvement is a main cause of mortality and morbidity. The therapeutic arsenal is mainly composed of classical immunosuppressants. However, when faced with resistance to these drugs, no alternative therapeutic strategy is currently recommended.

Objectives: To assess the efficacy and safety of interleukin 6 receptor inhibitor tocilizumab (TCZ) in refractory arterial involvement of BD in a real-life observational setting.

Methods: 10 patients were enrolled in our center between 2014 and 2019. All patients met the international criteria for $\mathrm{BD}$ and had severe arterial involvement evaluated by echocardiography, angio-Computerized Tomography scan and vascular Doppler. The diagnosis of refractory arterio-BD was based on objective vascular symptoms not explained by any other known disease and non-response to conventional immunosuppressants combined with glucocorticoids therapy. All patients underwent TCZ infusions at $8 \mathrm{mg} / \mathrm{kg}$ every 4 weeks. Concomitant ther apy with immunosuppressants and glucocorticoids was continued. Clinical and imaging findings were assessed before and after TCZ therapy. All adverse events were recorded during follow-up.

Results: All the patients were males, with a mean age of $44.3 \pm 10.5$ years in this study. The mean age at presentation of arterial involvement was $40.8 \pm 9.2$ years old. The patterns of arterial involvement were aneurysm $(n=9)$, stenosis $(n=3)$ and aortic valve lesion $(n=2)$. After a mean follow-up of $26.8 \pm 7.2$ months, TCZ yielded rapid and maintained clinical improvement in 9 patients with complete remission in 6 of them and partial response in 3 of them. Dis continuation of TCZ treatment due to relapse occurred in one case as the enlargement of abdominal aortic aneurysm. The mean glucocorticoid dosage was tapered from $54.5 \pm 20.6 \mathrm{mg} / \mathrm{d}$ to $8.3 \pm 3.6 \mathrm{mg} / \mathrm{d}(\mathrm{p}<0.001)$. And the use of immunosuppressants was tapered in $4(40.0 \%)$ patients. As for serological improvement, the median ESR and CRP levels decreased from $50(2-82$ $\mathrm{mm} / \mathrm{h}$ and $32.9(2.1-62.3) \mathrm{mg} / \mathrm{dL}$ to $4(1-10) \mathrm{mm} / \mathrm{h}(\mathrm{p}<0.001)$ and $2.9(0.2-12.1)$ $\mathrm{mg} / \mathrm{dL}(\mathrm{p}<0.001)$, respectively. Radiologic improvement of artery lesion was demonstrated in $4(40 \%)$ patients. None of the patients had serious adverse events during follow-up.

Conclusion: TCZ was a safe and effective therapeutic option for refractory arterial involvement of $\mathrm{BD}$, with a favorable steroid-sparing effect.

\section{REFERENCES:}

[1] G Hatemi, R Christensen, D Bang, et al. 2018 update of the EULAR recommendations for the management of Behçet's syndrome. Ann Rheum Dis 2018;77(6):808-818.

[2] $\mathrm{Y}$ Ozguler, $\mathrm{P}$ Leccese, $\mathrm{R}$ Christensen, et al. Management of majo organ involvement of Behcet's syndrome: a systematic review for update of the EULAR recommendations. Rheumatology (Oxford). 2018;57(12):2200-2212.

[3] M Akiyama, Y Kaneko, T Takeuchi. Effectiveness of tocilizumab in Behcet's disease: A systematic literature review. Semin Arthritis Rheum. 2020;50(4):797-804. 